\title{
Sistem Monitoring Kualitas Kekeruhan Air Berbasis Internet Of Thing
}

Tito Rikanto ${ }^{1}$, Arita Witanti ${ }^{2}$

${ }^{1}$ Informatika, Teknologi Informasi, Universitas Mercu Buana Yogyakarta

${ }^{21}$ Informatika, Teknologi Informasi, Universitas Mercu Buana Yogyakarta

${ }^{1}$ rikanto911@gmail.com, ${ }^{2}$ arita@ mercubuana-yogya.ac.id

\begin{abstract}
Water use is extensive nowadays. Many industries pollute the springs, and illegal logging is also a cause of declining water quality. The water condition in a reservoir can change. An automatic tool is needed to control water quality due to manual monitoring to ensure the water quality's suitability. This study is based on the Internet of Things (IoT), and used Arduino UNO, ESP8266, and LDR as the sensors. The module test used 30 samples of water in different conditions, with a total of 90 sample tests, and the test used the water flow concept. The research result was a module device that could monitor and control the water turbidity quality. It was expected to provide accurate results in monitoring the water quality in a reservoir and facilitate and help people avoid diseases due to poor water quality. Based on the results of the sample test calculations, the application of the IoT-based microcontroller in monitoring the water turbidity quality obtained the module's level of accuracy in detecting the water quality of $96.67 \%$.
\end{abstract}

Keywords: internet of things, microcontroller, water quality monitoring, water flow.

\begin{abstract}
Abstrak
Penggunaan air dimasa kini sangatlah besar, banyak industri yang mencemari daerah mata air dan penebangan hutan secara liar juga merupakan penyebab menurunnya kualitas air. Kondisi air pada bak tampung dapat berubah-ubah dan pemantauan masih secara manual untuk memastikan kualitas air baik untuk digunakan, maka diperlukan alat otomatis untuk mengontrol kualitas air. Studi ini berbasis Internet of Things menggunakan Arduino UNO,ESP8266 dan LDR sebagai sensornya. Pengujian modul menggunakan 30 sampel air berbeda kondisi dengan total uji sampel sebanyak 90 kali dan pengujian dengan konsep waterflow. Hasil penelitian berupa perangkat modul yang dapat memantau dan mengkontrol kualitas kekeruhan air diharapkan mampu memberikan hasil akurat dalam memonitoring kualitas air pada bak tampung serta dapat mempermudah dan membantu manusia untuk terhindar dari penyakit akibat kualitas air yang tidak baik Berdasarkan hasil perhitungan uji sampel, penerapan mikrokontroler berbasiskan Internet of Things dalam memonitoring kualitas kekeruhan air didapat tingkat keakurasian modul dalam mendeteksi kualitas air sebesar 96,67\%.
\end{abstract}

Kata kunci: internet of things, miikrokontroler, monitoring kualitas air, waterflow

\section{Pendahuluan}

\subsection{Latar Belakang}

Air adalah kebutuhan utama manusia dalam kehidupan sehari-hari. Pada umumnya, pengontrolan pompa air dan pemeriksaan kualitas air masih secara manual, hal ini menjadi kurang efisien dan sangat merepotkan masyarakat. Berdasarkan permasalahan tersebut,perlu dibuat sebuah alat elekronik yang dapat mengkontrol pompa air dan memantau tingkat kualitas air secara jarak jauh. Sistem ini menggunakan konsep teknologi Internet of Thing yang bertujuan dapat memudahkan masyarakat dalam mengkontrol dan memantau kualitas air dengan sistem kontrol jarak jauh dengan Telegram Messenger.

\subsection{Tinjauan Pustaka}

Penelitian terdahulu yang menjadi acuan pada penelitian ini salah satunya ialah penelitian mengenai merancang sebuah sistem penyiraman otomatis pada rumah kaca [1]. Sistem ini menggunakan Arduino dan ESP8266 sebagai sarana komunikasi ke server blynk yang dapat dipantau melalui android. Hasil Penelitian ini menunjukan bahwa proses monitoring dan penyiraman telah sukses dilakukan dan dapat tampil pada layar android. Proses penyiraman dipicu oleh kelembaban tanah yang dimonitor dengan penggunaan sensor soil moisture. Selain itu, aliran air dipantau dengan sensor waterflow.

Selanjutnya adalah penelitian mengenai merancang sebuah sistem monitoring nilai $\mathrm{pH}$ dan kadar kekeruhan air pada kolam ternak katak lembu [2]. Alat ini mampu memantau nilai $\mathrm{pH}$ dan kadar kekeruhan air pada kolam budidaya melalui platform Thingspeaks. Berdasarkan hasilnya, alat ini berfungsi untuk menghindari penyakit akibat kondisi lingkungan budidaya yang tidak baik.

Penelitian selanjutnya merancang sebuah sistem kontrol air secara realtime dengan menggunakan sensor LDR [3]. Penelitian ini bertujuan mengkarakterisasi sensor LDR dan selanjutnya hasilnya dipakai sebagai dasar dalam aplikasi perancangan sistem deteksi tingkat kekeruhan air. Dari hasil karakterisasi tersebut, dalam aplikasinya pada instrumen pengukur tingkat kekeruhan air diperoleh bahwa semakin tinggi tingkat kekeruhan air, maka intensitas yang terukur semakin kecil.

Penelitian terdahulu yang digunakan sebagai acuan selanjutnya mengenai merancang sebuah sistem pemantauan tingkat kekeruhan air dengan metode hamburan cahaya yang tersuspensi oleh partikel di dalam air menggunakan sensor kekeruhan DFRobot SEN0189 [4]. DFRobot SEN0189 mampu mendeteksi perubahan instensitas cahaya yang diakibatkan oleh 
adanya partikel-partikel dalam air yang kemudian diolah oleh mikrokontroller NodeMCU ESP8266 dan mengirimkan data secara aktual ke smartphone menggunakan protokol MQTT. Uji Eksperimental skala laboratorium menghasilkan tingkat presentase rata-rata penyimpangan sensor turbidity DFRobot SEN0189 adalah $<6.7 \%$. Sistem monitoring kekeruhan berbasis IoT dan aplikasi smartphone telah diuji menghasilkan updating delay 10 hingga 30 detik dengan sample kekeruhan air dijaga maksimum 5 NTU.

Untuk selanjutnya adalah penelitian mengenai merancang sebuah sistem efisiensi dan pemenuhan kebutuhan, monitoring tinggi air pada bak penampungan [5]. Monitoring ini dilakukan berbasis teknologi Internet of Things (IoT) yang mampu memberikan hasil secara akurat dan real-time. Alat yang digunakan berupa modul WiFi ESP8266 sebagai transmitter yang dipadukan dengan sensor ultrasonik. Sensor ultrasonik ini akan mendeteksi tinggi air dalam penampungan dengan memanfaatkan gelombang ultrasonik. Sistem diuji pada prototipe ground tank dengan ketinggian $300 \mathrm{~cm}$. Hasil uji memnunjukan respon sistem yang baik dan akurat sesuai posisi sensor. Sistem juga compatible dengan berbagai browser seperti Microsoft Edge, Mozilla Firefox, dan Google Chrome.

Penelitian ini fokus terhadap bagaimana konsep Internet of Thing mampu memantau dan mengontrol kualitas air dari jarak jauh dengan menggunakan aplikasi Telegram Messenger dengan pengujian air bergerak (waterflow) pada 30 sampel air berbeda kondisi.

\section{Metode Penelitian}

\subsection{Data Penelitian}

Bahan penelitian yang akan digunakan adalah pembuatan rancangan alat untuk memonitoring kualitas air berupa perangkat keras seperti laptop, smartphone, relay, NodeMCU ESP8266, sensor LDR, Arduino UNO R3 dan perangkat lunak diantaranya Arduino IDE dan Bot Telegram. Pada pembuatan sistem monitoring air dilengkapi dengan miniatur tampungan air beserta jalur air.

\subsection{Implementasi}

Pada tahap implementasi, tahap awal dilakukan pemrograman Arduino Uno dan ESP8266, dan pembuatan Bot Telegram. Untuk pemrograman paling utama pada ESP8266 adalah konfigurasi koneksi internet (jaringan $\mathrm{WiFi}$ ) sebagai penghubung antara Telegram dengan mikrokontroler. Setelah koneksi ke internet berhasil, dilanjutkan dengan membuat program untuk Bot Telegram sebagai pemberi perintah dan penerima feedback ke ESP8266 sebagai penerima perintah dan mengirim feedback Bot Telegram. ESP8266 hanya menerima perintah sesuai kode program yang tersedia, untuk perintah condition merupakan status dari kualitas air berdasarkan pembacaan nilai LDR oleh Arduino dan kemudian dikirim ke Telegram sesuai dengan status air tersebut.

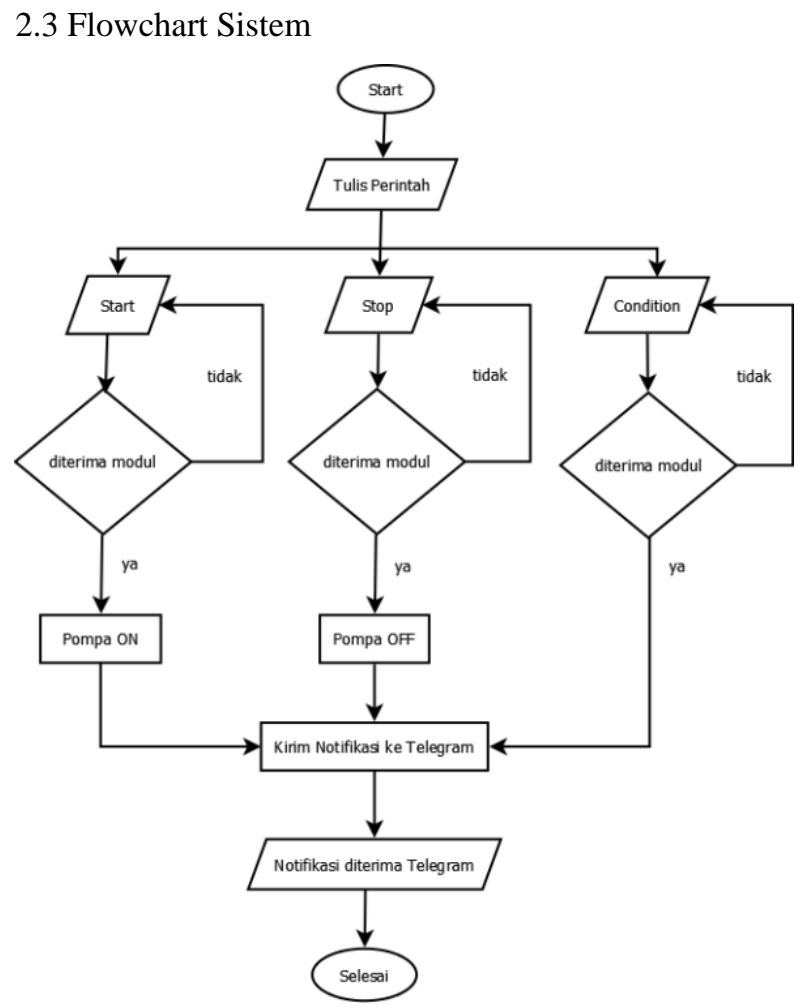

Gambar 1 Flowchart Sistem

\section{Hasil dan Pembahasan}

Hasil dari penelitian ini berdasarkan uji coba fungsi rangkaian alat monitoring melalui smartphone diperoleh hasil dari data pengujian sensor. Nilai lebih dari 180 maka dinyatakan kualitas air tidak baik, namun jika nilai kurang dari 180 maka kualitas air baik.

\subsection{Uji Sistem}

Pengujian sistem ini dimulai dengan memberikan perintah dari Bot Telegram berupa Start,Stop,Condition. Pengujian ini dilakukan dengan menggunakan 30 sampel air yang berbeda kondisi untuk mengukur tingkat kepekaan baca LDR dalam menangkap cahaya dan mengukur seberapa cepat respon modul menerima perintah dari Bot Telegram menggunakan stopwatch. Berikut tampilan Bot Telegram dengan dengan perintah Start,Stop, Condition. Hasil tabel 1 mengukur kecepatan respon modul Arduino UNO dan ESP8266 ketika diberi perintah dan mengirim pesan kembali ke Bot Telegram menggunakan stopwatch.

Tabel 1Hasil Pengukuran Kecepatan Respon Modul

\begin{tabular}{|c|c|c|c|c|}
\hline No & Perintah & $\begin{array}{l}\text { Pesan } \\
\text { (detik) }\end{array}$ & Diterima & Error $(\%)$ \\
\hline 1 & Start & 4,5 & & 0 \\
\hline 2 & Condition & 2,4 & & 0 \\
\hline
\end{tabular}




\begin{tabular}{llll}
3 & Stop & 3,3 & 0 \\
\hline 4 & Start & 2,4 & 0 \\
\hline 5 & Condition & 5,6 & 0 \\
\hline 6 & Stop & 3,9 & 0 \\
\hline 7 & Start & 6,3 & 0 \\
\hline 8 & Condition & 3,7 & 0 \\
\hline 9 & Stop & 4,2 & 0 \\
\hline 10 & Start & 3,8 & 0 \\
\hline 11 & Condition & 5,2 & 0 \\
\hline 12 & Stop & 7,5 & 0 \\
\hline 13 & Start & 5,2 & 0 \\
\hline 14 & Condition & 3,4 & 0 \\
\hline 15 & Stop & 7,7 & 0
\end{tabular}

\subsection{Hasil Uji Sistem}

Pada uji sistem tersebut mendapatkan hasil tabel pengujian sebagai berikut:

\begin{tabular}{|c|c|c|c|c|c|c|}
\hline \multirow[b]{3}{*}{ No } & \multirow[b]{3}{*}{ Sampel } & \multicolumn{3}{|c|}{ Tabel 2 Hasil Uji Sistem } & \multirow{2}{*}{\multicolumn{2}{|c|}{ Uji Sampel }} \\
\hline & & \multirow{2}{*}{$\begin{array}{c}\text { Turbiditas } \\
\text { (NTU) }\end{array}$} & \multirow{2}{*}{$\begin{array}{c}\text { Hasil } \\
\text { Kondisi } \\
\text { Air } \\
\text { (batas 5 } \\
\text { NTU) }\end{array}$} & \multirow[b]{2}{*}{$\begin{array}{l}\text { Nilai } \\
\text { LDR }\end{array}$} & & \\
\hline & & & & & Sesuai & $\begin{array}{l}\text { Tidak } \\
\text { Sesuai }\end{array}$ \\
\hline 1 & $\begin{array}{l}\text { Air } \\
\text { Minum } \\
\text { Kemas } \\
\text { an } \\
\end{array}$ & 0,03 & Jernih & $\begin{array}{l}142- \\
166\end{array}$ & 3 & 0 \\
\hline 2 & $\begin{array}{l}\text { Larutan } \\
\text { Garam }\end{array}$ & 7,93 & Keruh & $\begin{array}{l}176- \\
199\end{array}$ & 2 & 1 \\
\hline 3 & $\begin{array}{l}\text { Air } \\
\text { Sabun }\end{array}$ & 76,31 & Keruh & $\begin{array}{c}234- \\
278 \\
\end{array}$ & 3 & 0 \\
\hline 4 & $\begin{array}{l}\text { Air- } \\
\text { Minyak } \\
\text { Goreng }\end{array}$ & 69,01 & Keruh & $\begin{array}{l}191- \\
246\end{array}$ & 3 & 0 \\
\hline 5 & $\begin{array}{l}\text { Air- } \\
\text { Pasir }\end{array}$ & 103,04 & Keruh & $\begin{array}{l}184- \\
258\end{array}$ & 3 & 0 \\
\hline 6 & $\begin{array}{l}\text { Air- } \\
\text { Beras }\end{array}$ & 74,22 & Keruh & $\begin{array}{l}244- \\
289\end{array}$ & 3 & 0 \\
\hline 7 & $\begin{array}{l}\text { Air } \\
\text { Minum } \\
\text { Depot } \\
\text { Isi } \\
\text { Ulang } \\
\end{array}$ & 0,81 & Jernih & $\begin{array}{c}143- \\
178\end{array}$ & 3 & 0 \\
\hline 8 & $\begin{array}{l}\text { Air } \\
\text { Sirup }\end{array}$ & 121,41 & Keruh & $\begin{array}{l}452- \\
782\end{array}$ & 3 & 0 \\
\hline 9 & $\begin{array}{l}\text { Air } \\
\text { Kaporit }\end{array}$ & 5,59 & Keruh & $\begin{array}{l}164- \\
186\end{array}$ & 2 & 1 \\
\hline 10 & $\begin{array}{l}\text { Air- } \\
\text { Potong } \\
\text { an Tisu }\end{array}$ & 189,41 & Keruh & $\begin{array}{l}904- \\
968\end{array}$ & 3 & 0 \\
\hline 11 & $\begin{array}{l}\text { Air- } \\
\text { Potong } \\
\text { an } \\
\text { Daun } \\
\end{array}$ & 135,33 & Keruh & $\begin{array}{c}878- \\
985\end{array}$ & 3 & 0 \\
\hline 12 & $\begin{array}{l}\text { Air- } \\
\text { Serbuk } \\
\text { Bata }\end{array}$ & 122,43 & Keruh & $\begin{array}{l}196- \\
351\end{array}$ & 3 & 0 \\
\hline 13 & $\begin{array}{l}\text { Air } \\
\text { Kunir }\end{array}$ & 92,56 & Keruh & $\begin{array}{l}306- \\
422\end{array}$ & 3 & 0 \\
\hline
\end{tabular}

\begin{tabular}{|c|c|c|c|c|c|c|}
\hline 14 & $\begin{array}{l}\text { Kopi } \\
\text { hitam }\end{array}$ & 193,67 & Keruh & $\begin{array}{l}981- \\
984\end{array}$ & 3 & 0 \\
\hline 15 & $\begin{array}{l}\text { Larutan } \\
\text { Gula } \\
\text { Pasir }\end{array}$ & 13,21 & Keruh & $\begin{array}{c}194- \\
199\end{array}$ & 3 & 0 \\
\hline 16 & $\begin{array}{l}\text { Larutan } \\
\text { Gula } \\
\text { Aren }\end{array}$ & 47,89 & Keruh & $\begin{array}{l}403- \\
423\end{array}$ & 3 & 0 \\
\hline 17 & $\begin{array}{l}\text { Larutan } \\
\text { Teh } \\
\text { Encer }\end{array}$ & 67,99 & Keruh & $\begin{array}{l}221- \\
243\end{array}$ & 3 & 0 \\
\hline 18 & $\begin{array}{l}\text { Larutan } \\
\text { Teh } \\
\text { Kental }\end{array}$ & 99,34 & Keruh & $\begin{array}{c}681- \\
711\end{array}$ & 3 & 0 \\
\hline 19 & $\begin{array}{l}\text { Larutan } \\
\text { Susu } \\
\text { Bubuk } \\
\text { Putih }\end{array}$ & 144,42 & Keruh & $\begin{array}{c}582- \\
611\end{array}$ & 3 & 0 \\
\hline 20 & $\begin{array}{l}\text { Air } \\
\text { Kolam } \\
\text { Ikan }\end{array}$ & 197,22 & Keruh & $\begin{array}{l}877- \\
931\end{array}$ & 3 & 0 \\
\hline 21 & $\begin{array}{l}\text { Air } \\
\text { Soda } \\
\text { Merah }\end{array}$ & 167,88 & Keruh & $\begin{array}{l}743- \\
801\end{array}$ & 3 & 0 \\
\hline 22 & $\begin{array}{l}\text { Air } \\
\text { Soda } \\
\text { Hitam }\end{array}$ & 184,51 & Keruh & $\begin{array}{l}984- \\
1002\end{array}$ & 3 & 0 \\
\hline 23 & $\begin{array}{l}\text { Air- } \\
\text { Lumut }\end{array}$ & 127,73 & Keruh & $\begin{array}{c}651- \\
665\end{array}$ & 3 & 0 \\
\hline 24 & $\begin{array}{l}\text { Air } \\
\text { Jeruk } \\
\text { Nipis } \\
\end{array}$ & 97,41 & Keruh & $\begin{array}{l}347- \\
353\end{array}$ & 3 & 0 \\
\hline 25 & $\begin{array}{l}\text { Air } \\
\text { Sumur } \\
\end{array}$ & 2,98 & Jernih & $\begin{array}{c}146- \\
163 \\
\end{array}$ & 3 & 0 \\
\hline 26 & $\begin{array}{l}\text { Air } \\
\text { Sungai } \\
\text { (Hijau) }\end{array}$ & 87,33 & Keruh & $\begin{array}{c}576- \\
684\end{array}$ & 3 & 0 \\
\hline 27 & $\begin{array}{l}\text { Air } \\
\text { Laut }\end{array}$ & 30,54 & Keruh & $\begin{array}{c}426- \\
429\end{array}$ & 3 & 0 \\
\hline 28 & $\begin{array}{l}\text { Air } \\
\text { PDAM }\end{array}$ & 1,89 & Jernih & $\begin{array}{l}145- \\
166 \\
\end{array}$ & 3 & 0 \\
\hline 29 & $\begin{array}{l}\text { Air } \\
\text { Sawah }\end{array}$ & 11,41 & Keruh & $\begin{array}{l}671- \\
723 \\
\end{array}$ & 3 & 0 \\
\hline 30 & $\begin{array}{l}\text { Air } \\
\text { Hujan }\end{array}$ & 2,36 & Jernih & $\begin{array}{c}165- \\
182 \\
\end{array}$ & 2 & 1 \\
\hline \multicolumn{5}{|c|}{ Total } & 87 & 3 \\
\hline
\end{tabular}

Berdasarkan Tabel 2 pengujian dengan 30 sampel air berbeda kondisi dengan total uji coba 90 kali, masingmasing sampel air sebanyak 3 kali uji coba. Pengujian ini menggunakan metode waterflow dengan batasan nilai LDR untuk air jernih 180, sehingga jika nilai LDR lebih dari 180 maka air keruh dan mengacu pada hasil screening dengan Turbidimeter berdasarkan Peraturan Menteri Kesehatan RI No.492/MENKES/PER/IV/2010 Standar air jernih berdasarkan tingkat kekeruhan ditetapkan batas maksimal adalah 5 NTU (Nephelometric Turbidity Units). Pada pengujian tersebut didapat kesesuaian uji sampel dengan total uji sampel sesuai sebanyak 87 kali dan uji sampel tidak sesuai sebanyak 3 kali.

\begin{tabular}{cccc}
\multicolumn{4}{c}{ Tabel 3 Persentase Kesesuaian Sistem } \\
\hline No & Keterangan & Jumlah & Persentase \\
\hline 1 & Sesuai & 87 & $96,67 \%$ \\
\hline 2 & Tidak Sesuai & 3 & $3,33 \%$ \\
\hline
\end{tabular}


Berdasarkan Tabel 3 hasil keakurasian modul dari 30 sampel air mencakup 96,67\%. Dalam hal ini,semakin tinggi tingkat keakurasian modul maka semakin akurat modul tersebut dalam mendeteksi tingkat kualitas kekeruhan air.

\section{Kesimpulan}

Kesimpulan berdasarkan penelitian dan hasil uji sistem monitoring kualitas kekeruhan air diantaranya adalah Arduino UNO digunakan sebagai alat kontrol elektronik dan ESP8266 sebagai penerima perintah dari Bot Telegram dan mengirimkannya ke Arduino UNO untuk mengaktifkan relay didapatkan error sebesar $0 \%$. Berdasarkan hasil perhitungan, dapat disimpulkan bahwa modul dapat berjalan dengan baik desngan tingkat akurasi mencakup 96,67\%. Penelitian ini didasarkan pada pembacaan intensitas cahaya oleh LDR. Semakin tinggi nilai LDR,maka air keruh. Jika nilai LDR rendah, maka air jernih.

\section{Daftar Rujukan}

[1] Sasmoko, D., \& Horman, R. 2020. Sistem Monitoring Aliran Air dan Penyiraman Otomatis Pada Rumah Kaca Berbasis IOT dengan ESP8266 dan Blynk. Jurnal Ilmiah Pendidikan Teknik Elektro.
[2] Yasa, K. D., Janardana, I. N., \& Budiastra, I. N. 2020. Rancang Bangun Sistem Monitoring Nilai pH dan Kadar Kekeruhan Air Pada Kolam Ternak Kodok Lembu Berbasis IOT. Spectrum.

[3] Cahyono, B. E., Utami, I. D., Lestari, N. P., \& Oktaviany, N. S. 2019. Karakterisasi Sensor LDR dan Aplikasinya Pada Alat Ukur Tingkat Kekeruhan Air Berbasis Arduino UNO. Teori dan Aplikasi Fisika.

[4] Handoko, R. I., Hermadani, D. S., \& Hajjar, Y. 2019. Experimental Uji Kekeruhan Air Berbasis Internet Of Thing Menggunakan Sensor DFRobot SEN0189 dan MQTT Cloud Server. Seminar Nasional Sains dan Teknologi.

[5] Ulumuddin, Sudrajat, M., Rachmildha, T. D., Ismail, N., \& Hamidi, E. 2017. Prototipe Sistem Monitoring Air Pada Tangki Berbasis IoT Menggunakan NodeMCU Esp8266 dan Sensor Ultrasonik. SENTER2017.

[6] Arga.2020. Pengertian Arduino UNO dan Spesifikasinya. Diambil kembali dari Pintar Elektro Tersedia di : http://www.pintarelektro.com.[Accessed 1 April 2021]

[7] Wagino, \& Arafat. 2019. Monitoring dan Pengisian Air Tandon Otomatis Berbasis Arduino. Technologia.

[8] Kho, D. 2020. Struktur Mikrokontroler. Diambil kembali dari Teknik Elektronika

Tersedia di :www.teknikelektronika.com/pengertianmikrokontroler-microcontroller-srtukturmikrokonntroler/.[Accessed 21 Maret 2021]

[9] Effendi, Y. 2018. Internet Of Things Sistem pengendalian Lampu Menggunakan Rasberry PI Berbasis Mobile. Ilmiah Ilmu Komputer.

[10]Saleh, M., \& Haryanti, M.2017. Rancang Bangun Sistem Keamanan Rumah Menggunakan Relay. Teknologi Elektro Universitas Mercu Buana. 